\title{
Body Composition Assessed by Bioelectrical Impedance Analysis (BIA) in Patients with Graves' Disease Before and After Treatment ${ }^{\#}$
}

\author{
HONG-Yi HU AND YuzURU KATO \\ First Division, Department of Medicine, Shimane Medical University, \\ Izumo 693, Japan
}

\begin{abstract}
Body composition was assessed by bioelectrical impedance analysis (BIA) in 11 female patients with Graves' disease and in 49 age-matched healthy Japanese women. Patients with Graves' disease were examined in the hyperthyroid state before treatment and in the stable euthyroid state after treatment with antithyroid drugs for 6 to 18 months. Body weight (BW), percent body fat (BF/BW), percent lean body mass (LBM/BW) and percent total body water (TBW/BW) were not statistically different between hyperthyroid Graves' patients and healthy subjects. Percent body cell mass (BCM/ BW) was much lower in hyperthyroid Graves' patients than in healthy subjects (mean \pm SEM; $33.9 \pm$ $2.4 \%$ vs. $41.5 \pm 0.5 \%, P<0.001)$. Percent ratio of extracellular water to total body water $(\mathrm{ECW} / \mathrm{TBW}) \mathrm{was}$ much greater in hyperthyroid Graves' patients than in healthy subjects $(53.9 \pm 3.0 \%$ vs. $41.8 \pm 0.5 \%$, $P<0.001)$. These abnormal ratios, $\mathrm{BCM} / \mathrm{BW}$ and $\mathrm{ECW} / \mathrm{TBW}$, were normalized after treatment. Serum free $\mathrm{T}_{4}$ levels showed a positive correlation with ECW/TBW ( $\left.\mathrm{r}=0.779\right)$ and a reverse correlation with $\mathrm{BCM} / \mathrm{BW}(\mathrm{r}=-0.760)$ in all of the patients with Graves' disease examined. These findings indicate that body composition is affected by thyroid hormones and that body composition in hyperthyroid Graves' disease is characterized by decreased BCM associated with increased ECW.
\end{abstract}

Key words: Body composition, Bioelectrical impedance analysis, Body cell mass, Extracellular water, Free $\mathrm{T}_{4}$, Graves' disease

(Endocrine Journal 42: 545-550, 1995)

\begin{abstract}
ASSESSMENT of body composition by bioelectrical impedance analysis (BIA) has been validated by a strong correlation with hydro-densitometry and the isotope dilution method [1-7]. Recent studies also indicated a strong correlation between BIA and dual energy X-ray absorptiometry (DEXA) [8, 9]. By measuring resistance and reactance simultaneously, BIA delineates human body weight (BW) as composed of three compartments: body fat mass

Received: January 10, 1995

Accepted: May 1, 1995

Correspondence to: Dr. Yuzuru KATO, First Division, Department of Medicine, Shimane Medical University, 891 Enya-cho, Izumo 693, Japan

\#This work was presented in part at the 10th Asia-Oceania Congress of Endocrinology, Beijing, China, November, 1994.
\end{abstract}

(BF), body cell mass (BCM) and extracellular mass (ECM). BCM and ECM are called lean body mass (LBM). BCM is defined as the total mass of the protein-rich portion of the body and is associated with supporting intracellular water (ICW). ECM reflects the constituents of the body involved in transport and support, including extracellular water (ECW) and the skeleton [10]. The relative distribution of total body water (TBW) in intracellular and extracellular compartments can serve as an indicator of the compositional change [11].

It is well known that the body composition changes strikingly with the increase in gonadal hormone levels and secondary sexual maturation. Men have 1.5 times LBM and almost 1.5 times the skeletal mass of women, whereas women have twice as much BF as men [12, 13]. Recently, body 
composition assessed by BIA as well as the isotope dilution method showed an increase in BCM as well as the ECW/ICW ratio, and a decrease in BF in patients with acromegaly $[14,15]$. Whereas body composition of patients with GH deficiency was characterized by increased BF and decreased TBW $[15,16]$. Other investigators have indicated that body composition in cases of malnutrition is characterized by a depletion of BCM associated with an expansion of ECM $[17,18]$. Every patient with hyperthyroidism is generally associated with a varying degree of muscular atrophy [19], which is difficult to assess in the average patient. The body composition of patients with hyperthyroidism remains to be assessed by BIA.

In the present study, we applied BIA to the investigation of body composition in 11 patients with Graves' disease before and after treatment.

\section{Subjects and Methods}

\section{Subjects}

Eleven female patients with Graves' disease aged 15 to 71 (mean \pm SEM: $36.3 \pm 6.0 \mathrm{yr}$ ), and 49 healthy Japanese women aged 17 to $65 \mathrm{yr}(38.3 \pm 1.8 \mathrm{yr})$, were examined in the present study. The patients were examined in the hyperthyroid state before treatment and also in the stable euthyroid state after treatment with antithyroid drugs. Age and sex matched healthy subjects were selected from healthy medical staff and the general population.

All the patients were followed by our outpatient clinic for the evaluation of thyroid functions every one to three months. Either thimazole (TMA) or propylthiouracil (PTU) was prescribed to treat hyperthyroidism for 6 to 18 months. The antithyroid agents were ceased when serum free thyroxine $\left(\mathrm{FT}_{4}\right)$, thyrotropin (TSH) and thyrotropin binding inhibiting immunoglobulin (TBII) entered their normal ranges, and normal responses of serum TSH and triiodothyronine $\left(\mathrm{T}_{3}\right)$ to thyrotropin releasing hormone (TRH) were restored as described previously [20]. The euthyroid state remained for more than 3 months without any medication as confirmed by examination after treatment.

\section{Thyroid functions}

Basal serum $\mathrm{T}_{3}, \mathrm{~T}_{4}, \mathrm{FT}_{4}$ and $\mathrm{TSH}$ were measured by conventional RIA kits [20]. Normal ranges for serum $\mathrm{T}_{3}, \mathrm{~T}_{4}, \mathrm{FT}_{4}$ and TSH are 90-195 $\mathrm{ng} / \mathrm{dl}$, 5.4$13.5 \mu \mathrm{g} / \mathrm{d} l, 0.7-1.9 \mathrm{ng} / \mathrm{d} l$ and $0.32-3.70 \mu \mathrm{U} / \mathrm{ml}$, respectively. ${ }^{99} \mathrm{Tc}$ scintigraphy of the thyroid and serum TBII were also monitored [20].

\section{Bioelectrical impedance analysis}

The BIA was performed by means of Spectrum II 286 equipment (RJL System Inc., Detroit, Michigan, USA) as described previously [15]. The body composition was calculated by a computerized program, Weight Manager Professional, which was provided by the manufacturer. According to the three-compartment model, $\mathrm{BW}$ is considered to consist of BF, BCM and ECM [14]. Total body water (TBW) is the sum of ECW and ICW.

\section{Statistics}

The results are given as the mean \pm SEM. Statistical significance was evaluated by analysis of the variance in combination with Student's $t$-test. The correlation among variables was analyzed by standard linear regression. $P$ value less than 0.05 was considered significant.

\section{Results}

The thyroid functions were considerably elevated in our Graves' patients before treatment (hyperthyroid Graves' patients) with the mean ( \pm SEM) serum $\mathrm{T}_{3}, \mathrm{~T}_{4}, \mathrm{FT}_{4}$, TSH and TBII levels being $571.0 \pm 94.6 \mathrm{ng} / \mathrm{d} l, 22.1 \pm 1.7 \mu \mathrm{g} / \mathrm{d} l, 6.8 \pm 0.7 \mathrm{ng} /$ $\mathrm{d} l, 0.04 \pm 0.02 \mu \mathrm{g} / \mathrm{ml}$ and $47.6 \pm 8.6 \%$, respectively, and they were normalized after treatment (euthyroid Graves' patients: $\mathrm{T}_{3}, 118.8 \pm 6.3 \mathrm{ng} / \mathrm{d} l ; \mathrm{T}_{4}, 7.7$ $\pm 0.7 \mu \mathrm{g} / \mathrm{d} l ; \mathrm{FT}_{4}, 1.2 \pm 0.1 \mathrm{ng} / \mathrm{d} l ; \mathrm{TSH}, 1.43 \pm 0.43$ $\mu \mathrm{U} / \mathrm{ml}$; TBII, $8.0 \pm 2.5 \%$ ).

There was no statistical difference in BW, BMI, percent body fat (BF/BW), percent lean body mass (LBM/BW) and percent total body water (TBW/ BW) between the hyperthyroid Graves' patients and the healthy subjects (Fig. 1 and Table 1). The percent body cell mass (BCM/BW) was much lower in the hyperthyroid Graves' patients than in the healthy subjects $(33.9 \pm 2.4 \%$ vs. $41.5 \pm 0.5 \%$, $P<0.001)$. The percent ratio of extracellular water to total body water (ECW/TBW) was much greater in the hyperthyroid Graves' patients than in the 
healthy subjects $(53.9 \pm 3.0 \%$ vs. $41.8 \pm 0.5 \%$, $P<0.001)$, and these altered $\mathrm{BCM} / \mathrm{BW}$ and $\mathrm{ECW} /$ TBW were corrected in the euthyroid Graves' patients (39.9 $\pm 0.9 \%$ and $43.3 \pm 0.6 \%$, respectively).

In all the patients with Graves' disease, before and after treatment, there was a reverse correlation between $\mathrm{BCM} / \mathrm{BW}$ and serum $\mathrm{FT}_{4}$ levels $(\mathrm{r}=$ $-0.760, P<0.0001$, Fig. 2 ) and a positive correlation between ECW/TBW and serum $\mathrm{FT}_{4}$ levels

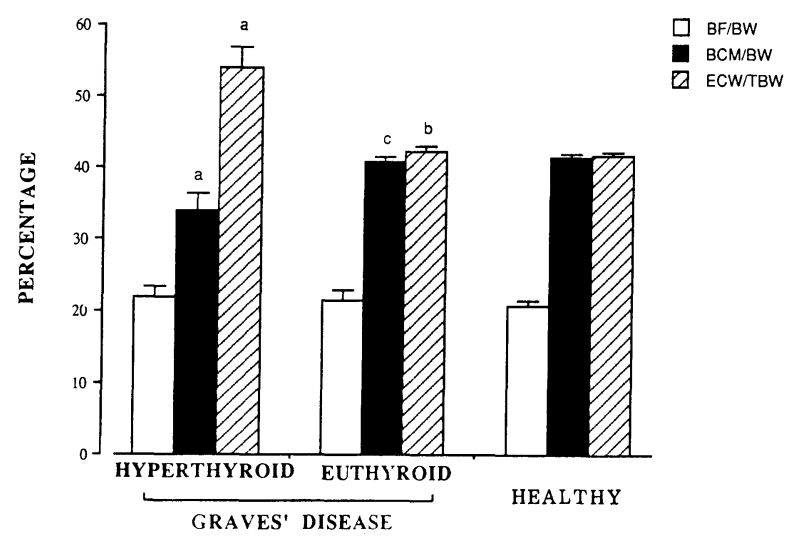

Fig. 1. Percent body fat (FB/BW), percent body cell mass $(\mathrm{BCM} / \mathrm{BW})$ and percent extracellular water $(\mathrm{ECW} /$ TBW) in 11 patients with Graves' disease in the hyperthyroid state and in the euthyroid state, and in 49 healthy Japanese women. Mean ( \pm SEM) values are shown. a, $P<0.001$ vs. healthy subjects; $b$, $P<0.025$ vs. hyperthyroid patients; c, $P<0.05$ vs. hyperthyroid patients.
( $\mathrm{r}=0.779, P<0.0001$, Fig. 3). Serum $\mathrm{T}_{3}$ and $\mathrm{T}_{4}$ levels also showed a reverse correlation with $\mathrm{BCM} / \mathrm{BW}$ $(\mathrm{r}=-0.686, P<0.0005$ and $\mathrm{r}=-0.640, P<0.002$, respectively) and a positive correlation with ECW/ TBW ( $\mathrm{r}=0.741, P<0.0001$ and $\mathrm{r}=0.738, P<0.0001$, respectively).

In the healthy subjects, there was a positive cor-

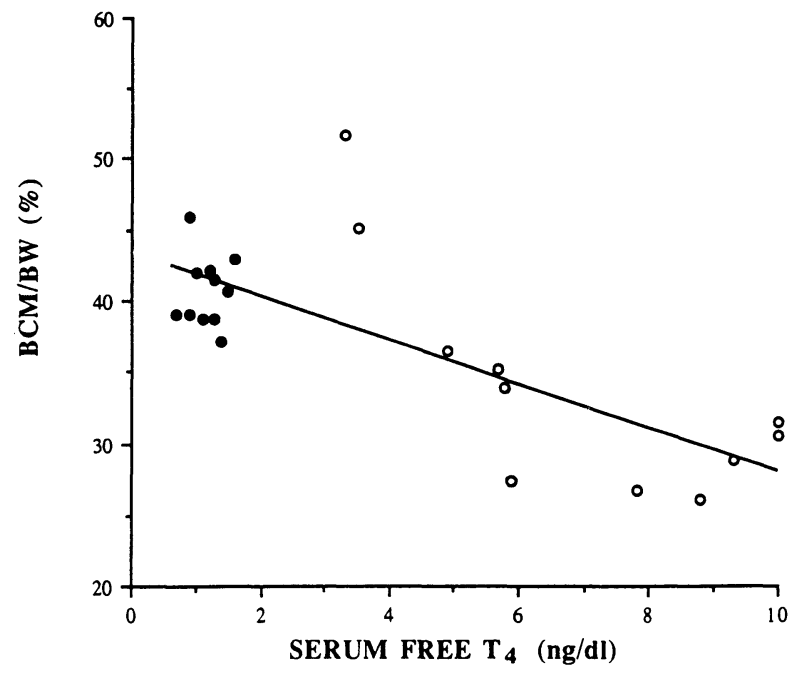

Fig. 2. Correlation between percent body cell mass (BCM/ $B W$ ) and serum free $T_{4}$ levels in 11 patients with hyperthyroid Graves' disease in the hyperthyroid state $(\bigcirc)$ and in the euthyroid state $(0)$. A linear regression line was obtained $(y=-1.532 x+43.425$, $\mathrm{r}=-0.760, P<0.0001)$.

Table 1. Body composition in 11 female patients with Graves' disease and 49 healthy women

\begin{tabular}{lccc}
\hline & \multicolumn{2}{c}{ Graves' disease } & Healthy \\
\cline { 2 - 3 } & Hyperthyroid & Euthyroid & \\
\hline n & 11 & 11 & 49 \\
Age $(y r)$ & $36.3 \pm 6.0$ & $40.1 \pm 3.4$ & $38.3 \pm 1.8$ \\
BW $(\mathrm{kg})$ & $49.5 \pm 2.2$ & $52.8 \pm 1.3$ & $51.6 \pm 0.5$ \\
BMI $\left(\mathrm{kg} / \mathrm{m}^{2}\right)$ & $20.5 \pm 0.6^{\mathrm{a}}$ & $22.6 \pm 0.6^{\mathrm{d}}$ & $21.7 \pm 0.2$ \\
Resistance $(\Omega)$ & $586.5 \pm 10.6$ & $546.1 \pm 14.3^{\mathrm{e}}$ & $564.0 \pm 7.0$ \\
Reactance $(\Omega)$ & $47.3 \pm 4.5^{\mathrm{b}}$ & $54.9 \pm 1.7^{\mathrm{a}}$ & $60.6 \pm 1.2$ \\
BF/BW $(\%)$ & $22.0 \pm 1.4$ & $21.2 \pm 1.3$ & $20.8 \pm 0.6$ \\
LBM/BW $(\%)$ & $78.0 \pm 1.4$ & $78.8 \pm 1.3$ & $79.2 \pm 0.6$ \\
BCM/BW $(\%)$ & $33.9 \pm 2.4^{\mathrm{c}}$ & $39.9 \pm 0.9^{\mathrm{d}}$ & $41.5 \pm 0.5$ \\
TBW/BW $(\%)$ & $57.1 \pm 1.0$ & $58.3 \pm 0.8$ & $58.0 \pm 0.4$ \\
ECW/TBW $(\%)$ & $53.9 \pm 3.0^{\mathrm{c}}$ & $43.3 \pm 0.6^{\mathrm{e}}$ & $41.8 \pm 0.5$ \\
\hline
\end{tabular}

Values are shown as the mean \pm SEM. a $P<0.05$, b $P<0.025, c, P<0.001$ vs. healthy subjects; ${ }^{\mathrm{d}}, P<0.05$, e $P<0.025$ vs. hyperthyroid. LBM/BW, percent lean body mass in body weight; $\mathrm{BCM} / \mathrm{BW}$, percent body cell mass in body weight; TBW/BW, percent total body water in body weight; ECW/TBW, percent ratio of extracellular water to total body water. 


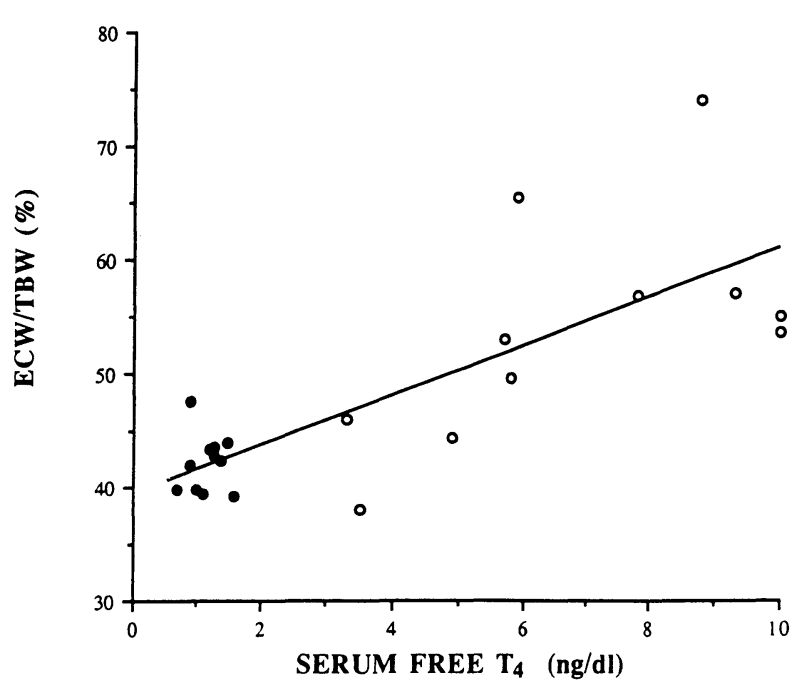

Fig. 3. Correlation between percent extracellular water (ECW/TBW) and serum free $\mathrm{T}_{4}$ levels in 11 patients with Graves' disease in the hyperthyroid state $(O)$ and in the euthyroid state $(0)$. A linear regression line was obtained $(y=2.142 x+39.472, r=0.779$, $P<0.0001)$.

relation between ECW/TBW and age $(r=0.313$, $P<0.05$, Fig. 4, upper panel). In contrast, no such correlation was obtained in the patients with hyperthyroid Graves' disease (Figs. 4, lower panel).

\section{Discussion}

In the present study, we found that the body composition of hyperthyroid Graves' patients is characterized by a lowered $\mathrm{BCM} / \mathrm{BW}$ and an elevated $\mathrm{ECW} / \mathrm{BW}$. These findings are consistent with those of patients with malnutrition derived from different diseases $[10,11,15,16]$. In contrast to a malnutritional state, however, BF/BW, LBM/ $\mathrm{BW}$ and TBW/BW in the hyperthyroid patients were not different from those of healthy subjects.

Thyroid hormones play an important role in a variety of metabolic processes in the body, influencing the growth and maturation of tissues, total energy expenditure, etc. [21]. No tissue or organ system escapes the adverse effects of thyroid hormone excess. In the hypermetabolic state induced by hyperthyroidism, calorigenesis is enhanced by transmembrane $\mathrm{Na}^{+}-\mathrm{K}^{+}$-ATPase activity due to an increased number of pumps [22-24]. Glucose utilization, especially in the skeletal muscle, is
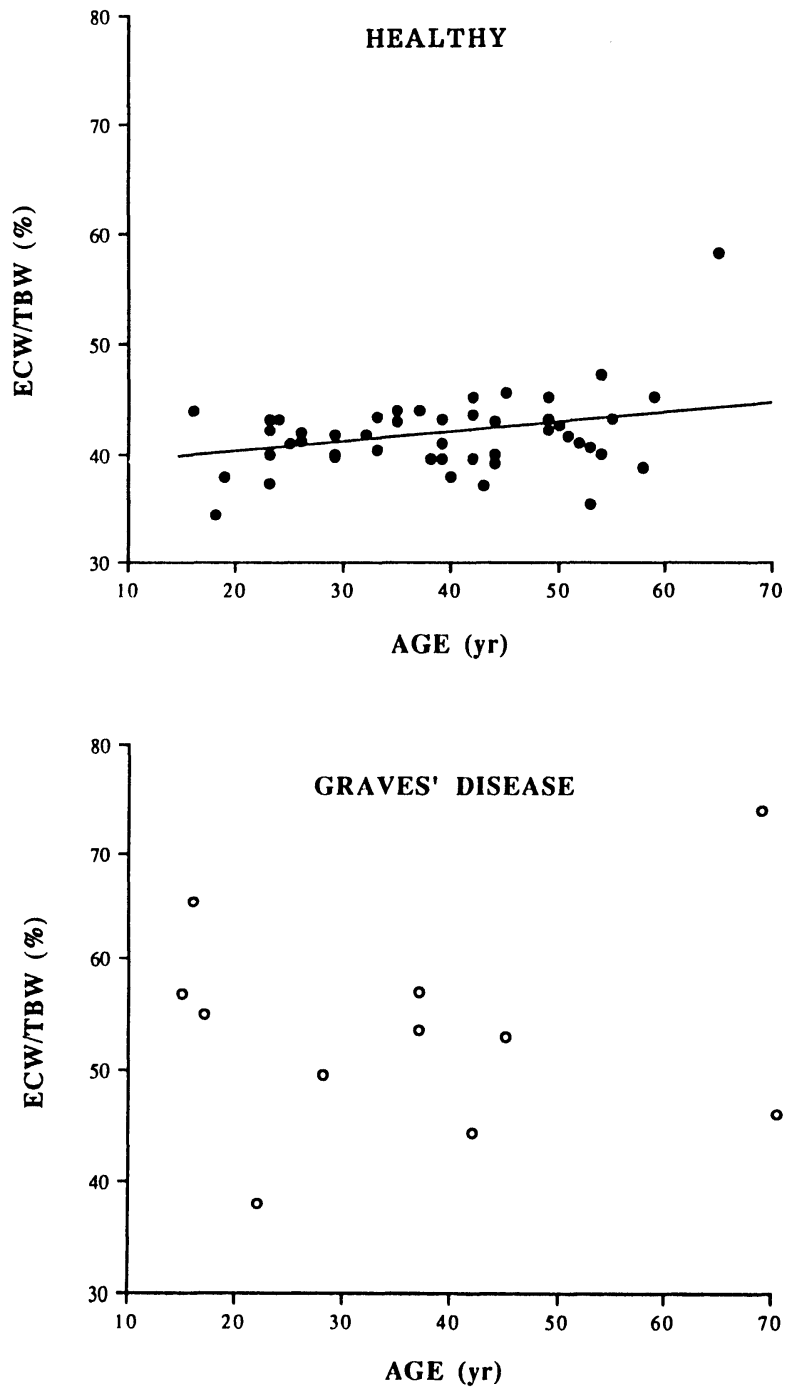

Fig. 4. Correlation between percent extracellular water (ECW/TBW) and age in 49 healthy women (upper panel), and in 11 female patients with hyperthyroid Graves' disease (lower panel). A linear regression line was obtained in healthy women $(y=0.089 x+$ 38.423, $\mathrm{r}=0.313, P<0.05)$.

stimulated $[25,26]$ and protein synthesis is inhibited with increased nitrogen excretion. The increased transmembrane exchange of extracellular $\mathrm{K}^{+}$for intracellular $\mathrm{Na}^{+}$in hyperthyroidism may result in an abnormal electrochemical gradient, which is characterized by a loss of ICW in the BCM and an expansion of ECW in the ECM.

It has been reported that $\mathrm{BCM}$ changes correlate with energy and protein intakes [10]. In hyperthyroidism, despite an increased food intake, a state of chronic caloric and nutritional inadequacy en- 
sues resulting in a negative nitrogen balance, muscle wasting, weakness and loss of weight. BCM depletion and ECW expansion in the hyperthyroid Graves' patients may have been the result of increased energy expenditure or protein catabolism induced by thyroid hormones excess, and it is deducible that BCM and ECW are relatively more sensitive to the metabolic action of thyroid hormones than BF and TBW.

We previously reported that $\mathrm{BF} / \mathrm{BW}$ is correlated with age in healthy subjects [15]. In the present study, ECW/TBW showed a correlation with age in healthy subjects whereas there was no correlation in hyperthyroid Graves' patients, although the variations of the values were large in a small number of subjects.

The present study indicates that BIA reflects altered body composition in patients with Graves' disease, suggesting that $\mathrm{BCM} / \mathrm{BW}$ and $\mathrm{ECW} / \mathrm{TBW}$ may serve as a sensitive indicator of metabolic conditions in patients with Graves' disease before and after treatment. Further studies with a large number of patients are however required to address this issue.

\section{Acknowledgments}

We are indebted to Sumitomo Pharmaceutical Co., for providing us the chance to use Spectrum II 286. We also thank Miss Akemi Imaoka and Mrs. Akiko Kawakami for technical assistance and secretarial assistance, respectively. This work was supported in part by the Ministry of Education, Science and Culture, Japan, the Ministry of Health and Welfare, Japan and the Shimane Institute of Intractable Diseases.

\section{References}

1. Lukaski HC, Bolonchuk WW, Hall CB, Siders WA (1986) Validation of tetrapolar bioelectrical impedance method to assess human body composition. J Appl Physiol 60: 1327-1332.

2. Lukaski HC, Johnson P, Bolonchuk WW, Lykken GI (1985) Assessment of fat-free mass using bioelectrical impedance measurement of the human body. Am J Clin Nutr 41: 810-817.

3. Lukaski HC (1987) Methods for the assessment of human body composition: traditional and now. Am J Clin Nutr 46: 537-556.

4. Kushner RF, Schoeller DA (1986) Estimation of total body water by bioelectrical impedance analysis. Am J Clin Nutr 44: 417-424.

5. Segal KR, Loan MV, Fitzgerald PI, Hodgdon JA, Van Itallie TB (1988) Lean body mass estimation by bioelectrical impedance analysis: a four-site crossvalidation study. Am J Clin Nutr 47: 7-14.

6. Baumgartner RN, Chumlea WC, Roche AF (1989) Estimation of body composition from bioelectrical impedance of body segments. Am J Clin Nutr 50: 221-226.

7. Segal KR, Gutin B, Presta E, Wang J, Van Itallie TB (1985) Estimation of human body composition by electrical impedance methods: a comparative study. J Apply Physiol 58: 1565-1571.

8. Stewart SP, Bramley PN, Heighton R, Green JH, Horsman A Losowsky MS, Smith MA (1993) Estimation of body composition from bioelectrical impedance of body segments: comparison with dual-energy X-ray absorptiometry. Br J Nutr 69: 645-655.

9. Pritchard JE, Nowson CA, Strauss BJ, Carlson JS, Kaymakci B, Wark JD (1993) Evaluation of dual energy X-ray absorptiometry as a method of measurement of body fat. Eur J Clin Nutr 47: 216-228.

10. Robert S, Zarowitz B, Hyzy R, Eichenhorn M, Peterson E, Popovich Jr J (1993) Bioelectrical impedance assessment of nutritional status in critically patients. Am J Clin Nutr 57: 840-844.

11. Elwyn DH, Bryan-Brown CW, Shoemaker WC (1975) Nutritional aspects of body water dislocations in postoperative and depleted patients. Ann Surg 182: 76-85:

12. Garn SM (1957) Fat weight and fat placement in the female. Science 169: 1091-1092.

13. Ridder CM, Brunning PF, Zonderland ML, Thijssen JHH, Bonfrer JMG, Blankstein MA, Huisveld IA, Erich WBM (1990) Body fat mass, body fat distribution, and plasma hormones in early puberty in females. J Clin Endocrinol Metab 70: 888-893.

14. Bengstson BÅ, Brummer RJ, Edén S, Bosaeus I (1989) Body composition in acromegaly. Clin Endocrinol 30: 121-130.

15. Hu H-Y, Yamamoto $H$, Sohmiya $M$, Abe $T$, Murakami Y, Kato Y (1994) Body composition assessed by bioelectrical impedance analysis (BIA) and the correlation with plasma insulin-like growth factor I (IGF-I) in normal Japanese subjects and patients with acromegaly and GH deficiency. Endocr J 41: 
63-69.

16. Boer HD, Blok GJ, Voerman HJ, De Vries PMJM (1992) Body composition in adult growth hormonedeficient man, assessed by anthropometry and bioimpedance analysis. J Clin Endocrinol Metab 75: 833-837.

17. Ott $M$, Lembcke $B$, Fischer $H$, Jäger $R$, Polat $H$, Geier H, Rech M, Staszewki S, Helm EB, Caspary WF (1993) Early Changes of body composition in human immunodeficiency virus-infected patients: tetrapolar body impedance analysis indicates significant malnutrition. Am J Clin Nutr 57: 15-19.

18. Shizgal HM (1985) Body composition of patients with malnutrition and cancer. Cancer 55: 250-253.

19. Ramsay ID (1966) Muscle dysfunction in hyperthyroidism. Lancet ii: 931-934.

20. Notsu K, Oka N, Masaki Y, Furuya H, Kato Y (1991) Plasma Free triiodothyronine response to thyrotropin releasing hormone to predict the remission of Graves' disease treated with antithyroid drugs. I Clin Endocrinol Metab 73: 396-400.

21. Tata JR, Erster L, Lindberg O, Arrhenius E, Pedersen
S, Hedman P (1963) The action of thyroid hormones at the cell level. Biochem J 86: 408-428.

22. Ismail-Beigi $F$, Edelman IS (1971) The mechanism of the calorigenic action of thyroid hormones: stimulation of $\mathrm{Na}^{+}+\mathrm{K}^{+}$-activated adenosinetriphosphatase activity. J Gen Physiol 57: 710-722.

23. Azuma KK, Hensley CB, Tang M-J, McDonough AA (1993) Thyroid hormone specifically regulates skeletal muscle $\mathrm{Na}^{+}-\mathrm{K}^{+}$-ATPase $\alpha_{2}$ and $\beta_{2}$-isoforms. Am J Physiol 265: c680-687.

24. Matsumura M, Kuzuya N, Kawakami Y, Yamashita $K$ (1992) Effects of fasting, refeeding, and fasting with $\mathrm{T}_{3}$ administration on $\mathrm{Na}^{+}-\mathrm{K}^{+}$-ATPase in rat skeletal muscle. Metabolism 41: 995-999.

25. Müller MJ, Acheson KJ, Jequier E, Burger AG (1988) Effects of thyroid hormones on oxidative and nonoxidative glucose metabolism in humans. $\mathrm{Am} \mathrm{J}$ Physiol 255: E146-152.

26. Weinstein SP, Watts J, Haber RS (1991) Thyroid hormone increases muscle/fat glucose transporter gene expression in rat skeletal muscle. Endocrinology 129: 455-464. 